Research Article

\title{
Embodied Energy and Cost Optimization of RC Beam under Blast Load
}

\author{
Runqing Yu, Diandian Zhang, and Haichun Yan \\ State Key Laboratory of Disaster Prevention \& Mitigation of Explosion \& Impact, PLA University of Science and Technology, \\ Nanjing, Jiangsu 210007, China \\ Correspondence should be addressed to Runqing Yu; jkggklj@qq.com
}

Received 13 October 2016; Accepted 12 February 2017; Published 22 March 2017

Academic Editor: Sergii V. Kavun

Copyright (C) 2017 Runqing Yu et al. This is an open access article distributed under the Creative Commons Attribution License, which permits unrestricted use, distribution, and reproduction in any medium, provided the original work is properly cited.

\begin{abstract}
Reinforced concrete (RC) structures not only consume a lot of resources but also cause continuing pollution. However, sustainable design could make RC structures more environmental-friendly. One important index for environmental impact assessment is embodied energy. The aim of the present study is to optimize the embodied energy and the cost of RC beam subjected to the blast loads. First, a general optimization procedure was described. Then, the optimization procedure was used to optimize the embodied energy and the cost of RC beams. Optimization results of the cost and the embodied energy were compared. It was found that the optimization results were influenced by the cost ratio $n_{C}$ (ratio of price of steel to price of concrete per unit volume) and the embodied energy ratio $n_{E}$ (ratio of embodied energy of steel to embodied energy of concrete per unit volume). An optimal design that minimized both embodied energy and cost simultaneously was obtained if values of $n_{C}$ and $n_{E}$ were very close.
\end{abstract}

\section{Introduction}

Worldwide, RC structures consume a lot of energy [1] and give off large amounts of greenhouse gases [2]. In addition, the maintenance, repair, and refurbishment during the life of buildings also consume a lot of energy. Even when the building is abandoned, quantities of solid construction waste are difficult to recycle. All of those burden the environment.

In order to make RC structures more friendly to environment, a lot of efforts have been made to reduce the influence of RC buildings on environment during the service life [3]. Recently, many researchers focused on the optimization of RC structures considering environment factors [4-7]. PayaZaforteza et al. [4] minimized the carbon dioxide (CO2) emissions and the cost using simulated annealing. Their research showed that the $\mathrm{CO} 2$ emissions optimization and the cost optimization were highly related. Yeo and Gabbai [5] explored the implications of using the embodied energy as the objective function to be minimized from the point of view of cost. Their results showed that a reduction of $10 \%$ in the embodied energy leads to an increase of $10 \%$ in the cost. In their study, certain values of the embodied energy were used, which was not true in practice because the exact value of embodied energy was not known $[8,9]$. Medeiros and Kripka [6] proposed an optimal method to minimize the monetary and environmental costs of RC column. In their study, four environmental impact assessment indices- $\mathrm{CO} 2$, global warming potential (GWP), energy consumption, and Eco-indicator-were taken into consideration, but the cost was not considered. Yepes et al. [7] suggested a design method to optimize the cost and the $\mathrm{CO} 2$ emission of precastprestressed concrete U-beam road bridges. Their analysis showed that a reduction of costs by 1 Euro can save up to $1.75 \mathrm{~kg}$ in $\mathrm{CO} 2$ emissions. Park et al. [10] provided structural design guidelines that reduced the $\mathrm{CO} 2$ emission and the cost of RC columns. Parametric study was conducted to investigate the influences of design factors on the $\mathrm{CO} 2$ emission and the cost.

In conclusion, those researches optimized RC structures in normal operation condition considering environment factors. Extreme loading conditions, such as explosion, earthquake, and hurricane, were not considered. In the last century, the design that used to resist the extreme loads was not common. With the rapid development of economy, 
the design to resist the extreme loads was widely accepted by engineering field. An increasing number of buildings were designed considering the extreme loading conditions. Therefore, studies on the sustainable design of RC structures in extreme loading conditions are necessary.

In this study, a sustainable design of RC beam under blast loads was discussed through minimizing the embodied energy. Meanwhile, the cost was used as objective function for comparison. First, a general optimal design procedure was presented. Then, parametric studies were conducted to analyze the influences of the material strength and sectional geometry on the optimal design. The cost and embodied energy of particular building materials (reinforcements and concrete) were taken as variables and their influences on the optimal design were presented. The optimization results of cost and the embodied energy were compared and the correlation between them was discussed, which may be helpful for sustainable deign of RC structural members against blast.

\section{Methodology}

2.1. Problem Description. In this study, an interior beam subjected to air blast load was considered. This problem was an illustrative example of UFC 3-340-02 [11]. Both ends of the beam were fixed. The beam was assumed to deform in a flexural shape. The cross section is shown in Figure 1. A uniform blast load is applied on the upper surface of the beam. The beam was designed according to the restrictions and guidelines found in the UFC 3-340-02 code.

There are two response indices that are usually used to define the damage levels of blast-loaded structural components in a flexural response regime: the support rotation angle $(\theta)$ and the ductility ratio $(\mu)[12]$. In the present study, both of the two indices were used as design constraints.

Four design parameters were considered in this study. The four parameters were the height of the beam $h$, the width $b$, the ratio of longitudinal reinforcement $\rho_{1}$, and the ratio of stirrup $\rho_{2}$.

2.2. Objective Functions. The total cost and the total embodied energy were taken as objective function to be minimized. The total cost is defined as [13]

$$
C^{\prime}=C_{C} V_{C}+C_{S}\left(V_{S 1}+V_{S 2}\right)
$$

where $C^{\prime}$ is the total cost of beam, $C_{C}$ is the cost of concrete per unit volume, $V_{C}$ is the volume of concrete, $C_{S}$ is the cost of reinforcing steel per unit volume, and $V_{S 1}$ and $V_{S 2}$ are the volume of longitudinal reinforcement and shear reinforcement, respectively.

It should be noted that the optimal values were affected by the relative values of the objective function only. Equation (1) divided by $C_{S}$ is

$$
C^{\prime \prime}=\frac{V_{C}}{n_{C}}+\left(V_{S 1}+V_{S 2}\right),
$$

where $n_{C}=C_{s} / C_{c}, C^{\prime \prime}=C^{\prime} / C_{S}$.

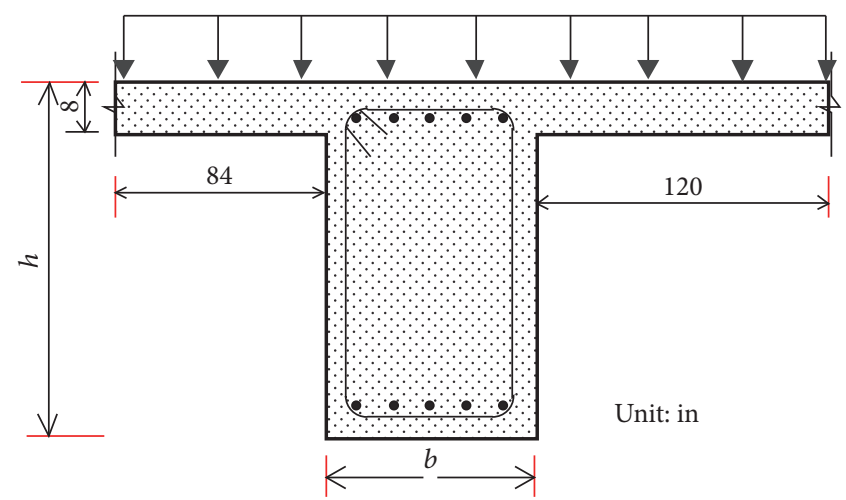

FIgURE 1: Cross section.

The value of $n_{C}$ varies from country to country; thus, (2) was more convenient to study the minimum cost of RC beam than (1) [13].

Similarly to the cost objective function, the embodied energy objective function is written as follows:

$$
E^{\prime \prime}=\frac{V_{C}}{n_{E}}+\left(V_{S 1}+V_{S 2}\right),
$$

where $E^{\prime \prime}=E^{\prime} / E_{S}, E^{\prime}$ is the total energy, $E_{S}$ is the embodied energy of steel per unit volume, $n_{E}=E_{S} / E_{C}$ is the energy ratio, and $E_{C}$ is the embodied energy of concrete per unit volume.

Comparing (2) with (3), a similarity can be found. The form of the energy objective function and the cost objective function is very similar. Thus, the cost objective function and the energy objective function are represented by (4) for the convenience of optimization calculation.

$$
W=\frac{V_{C}}{n}+\left(V_{S 1}+V_{S 2}\right),
$$

where $n$ denotes $n_{C}$ and $n_{E}$ and $W$ denotes $C^{\prime \prime}$ and $E^{\prime \prime}$.

In the following analysis, the optimal designs for the cost $C^{\prime \prime}$ and the embodied energy $E^{\prime \prime}$ were unified to the optimal design for $W$.

2.3. Design Constraints. The RC beam under blast load is simplified to SDOF system (see Figure 2). The design constraints were given in mathematical expressions and the optimal design was transform into a constrained optimization problem.

The design constraints were defined in accordance with the UFC 3-340-02 code [11]. The constraints for RC rectangular section beam under blast load were expressed.

(1) Performance limits are as follows:

$$
\begin{aligned}
& \theta \leq \theta_{a}, \\
& \mu \leq \mu_{a} .
\end{aligned}
$$




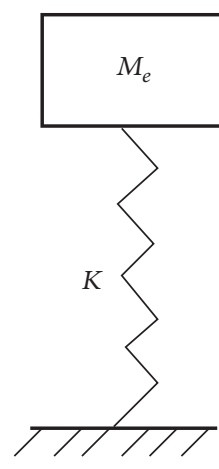

(a) Equivalent system

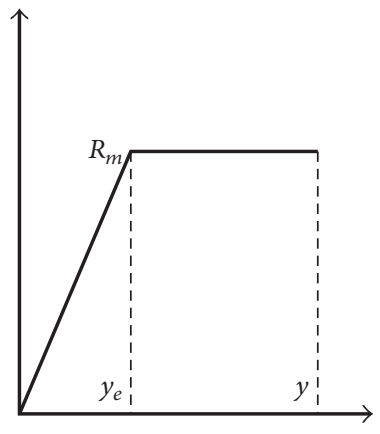

(b) Resistance curve

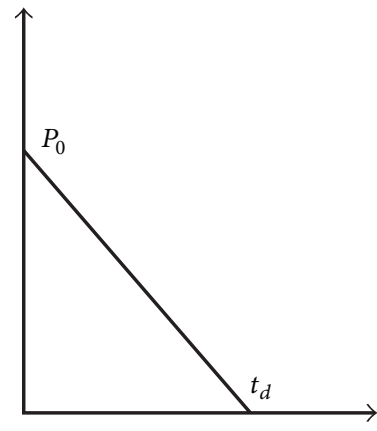

(c) Blast load

FIgURE 2: The simplified SDOF model of RC beam under blast load.

(2) Constraints of the ratio of longitudinal reinforcement $\rho_{1}$ and the ratio of stirrup $\rho_{2}$ are as follows:

$$
\begin{aligned}
& 0.75\left(\frac{0.85 K_{1} f_{\mathrm{dc}}^{\prime}}{f_{\mathrm{dy}}}\right)\left(\frac{87000}{87000+f_{\mathrm{dy}}}\right) \geq \rho_{1} \\
& \geq \max \left(\frac{3 \sqrt{f_{c}^{\prime}}}{f_{y}}, \frac{200}{f_{y}}\right), \\
& \rho_{2} \geq 0.0015 .
\end{aligned}
$$

(3) Limit of the direct shear stress is as follows:

$$
0.18 f_{\mathrm{dc}}^{\prime} b d \leq \frac{R_{m}}{2} l .
$$

(4) Limit of the diagonal tension stress is as follows:

$$
\frac{(l / 2-d) R_{m}}{b d} \leq 10\left(f_{\mathrm{dc}}^{\prime}\right)^{0.5} .
$$

(5) Limit of the unreinforced web shear capacity is as follows:

$$
1.9\left(f_{\mathrm{dc}}^{\prime}\right)^{0.5}+2500 \rho_{1} \leq 3.5\left(f_{\mathrm{dc}}^{\prime}\right)^{0.5}
$$

where $\theta_{a}$ is the allowable support rotation angle, $\mu_{a}$ is the allowable ductility ratio, $f_{c}^{\prime}$ is the concrete compressive strength, $f_{\mathrm{dc}}^{\prime}$ is the dynamic concrete compressive strength, $f_{y}$ is the yield stress of steel, $f_{\mathrm{dy}}$ is the dynamic yield stress of steel, $K_{1}$ is a coefficient associated with $f_{c}^{\prime}, b$ is the width of beam, $d$ is the distance from the extreme compression fiber to the centroid of the longitudinal tension reinforcement, $R_{m}$ is the bending resistance of RC beam, and $l$ is the span length.

Some explanations of design constraints are presented here. Equations (5) are the deformation requirements. The value of $\theta_{a}$ and $\mu_{a}$ can be found in many literatures $[11,14,15]$. Equations (7) (9) are the requirements that ensure shear failure does not occur.

It should be noticed the parameters shown in (5) (9) were interrelated. This interrelated relationship was reflected in the calculation of $\rho_{2}, \theta, R_{m}$, and $\mu$. Calculations of $\rho_{2}, \theta, R_{m}$, and $\mu$ were present.

(1) $\rho_{2} \cdot \rho_{2}$ was computed by

$$
\rho_{2}=\frac{\max \left(v_{u}-v_{c}, v_{c}\right)}{0.85 f_{\mathrm{dy}}},
$$

where $v_{c}$ and $v_{u}$ are calculated by (11) and (12), respectively.

$$
\begin{aligned}
& v_{c}=1.9\left(f_{c}^{\prime}\right)^{0.5}+2500 \rho_{1}, \\
& v_{u}=\frac{(l / 2-d) R_{m}}{b d} .
\end{aligned}
$$

(2) $\theta . \theta$ is defined in

$$
\theta=\arctan \left(2 \frac{y_{m}}{l}\right),
$$

where $y_{m}=\mu y_{e}, y_{m}$ is the maximum midspan displacement, and $y_{e}$ is the elastic midspan displacement.

$y_{e}$ is calculated by

$$
y_{e}=\frac{R_{m}}{K}
$$

where $K$ is the equivalent elastic stiffness.

$K$ is given by (15) considering clamped boundary.

$$
K=\frac{307 E_{C} I_{a}}{l^{4}},
$$

where $E_{C}$ is the concrete modulus of elasticity and $I_{a}$ is the average moment of inertia of the beams.

$I_{a}$ is given by

$$
I_{a}=0.5\left(\frac{b h^{3}}{12}+G b d^{3}\right) .
$$

The coefficient $G$ in (16) is evaluated by [16]

$$
G=\left(3320.3 \rho_{1}^{3}-181.98 \rho_{1}^{2}+5.8624 \rho_{1}\right)\left(\frac{E_{S}}{7 E_{C}}\right)^{0.7},
$$

where $E_{S}$ is the steel modulus of elasticity. 
(3) $R_{m}$. The resistance $R_{m}$ is given by [11]

$$
R_{m}=\frac{8\left(M_{N}+M_{P}\right)}{l^{2}},
$$

where $M_{N}$ is ultimate negative moment capacity at the support and $M_{P}$ is ultimate positive moment capacity at the midspan.

Values of $M_{N}$ and $M_{P}$ are calculated by (19) considering symmetrical reinforced concrete beam.

$$
M_{N}=M_{P}=\rho_{1} f_{\mathrm{dy}} b d^{2}\left(1-\frac{\rho_{1} f_{\mathrm{dy}}}{1.7 \rho_{1} f_{c}^{\prime}}\right) .
$$

(4) $\mu . \mu$ is calculated by [17]

$$
\frac{2}{\omega t_{d}} \sqrt{2 \mu-1}+\frac{2 \mu-1}{2 \mu\left(1+\left(1.4 \pi / \omega t_{d}\right)\right)}=\frac{P_{0}}{R_{m}},
$$

where $\omega$ is the natural frequency, $t_{d}$ is the duration time, and $P_{0}$ is the peak pressure.

$\omega$ is calculated by

$$
\omega=\sqrt{\frac{K}{\left(K_{\mathrm{LM}} m\right)}},
$$

where $m$ is the mass of the beam plus $20 \%$ of the slabs span perpendicular to the beam and $K_{\mathrm{LM}}$ is the load-mass factor.

2.4. Optimization Technique and Verification. Many methods were used successfully in optimal design of RC structures, such as Generalized Reduced Gradient (GRG) method [13], heuristic optimization methods $[18,19]$, discretized continuum-type optimality criteria (DCOC) [20], and Lagrange multiplier method [21]. In this study, the sequential quadratic programing (SQP) method was used since SQP was efficient proved by an extensive comparative study done by Schittkowski [22]. Besides, SQP was easy to realize by the constrained nonlinear optimization solver "fmincon" in MATLAB.

In order to get the global optimum, many random starting points were used. The random starting points were generated by Latin hypercube sampling (LHS) [23]. LHS was a matrix of $i \times j$ order. $i$ was the number of sampling points to be examined. $j$ was the number of design parameters. Each of $j$ columns of matrix that contained sampling points $1,2, \ldots, i$ was coupled to form the Latin hypercube. This generated random sample points, which ensured that all portions of design space were represented.

The flowchart of optimum design method is shown in Figure 3.

\section{Numerical Examples and Discussions}

3.1. Example 1: Verify the Effectiveness of Optimum Design Method. Values of design parameters in this example are listed in Table 1 , where $\rho$ is density of concrete.

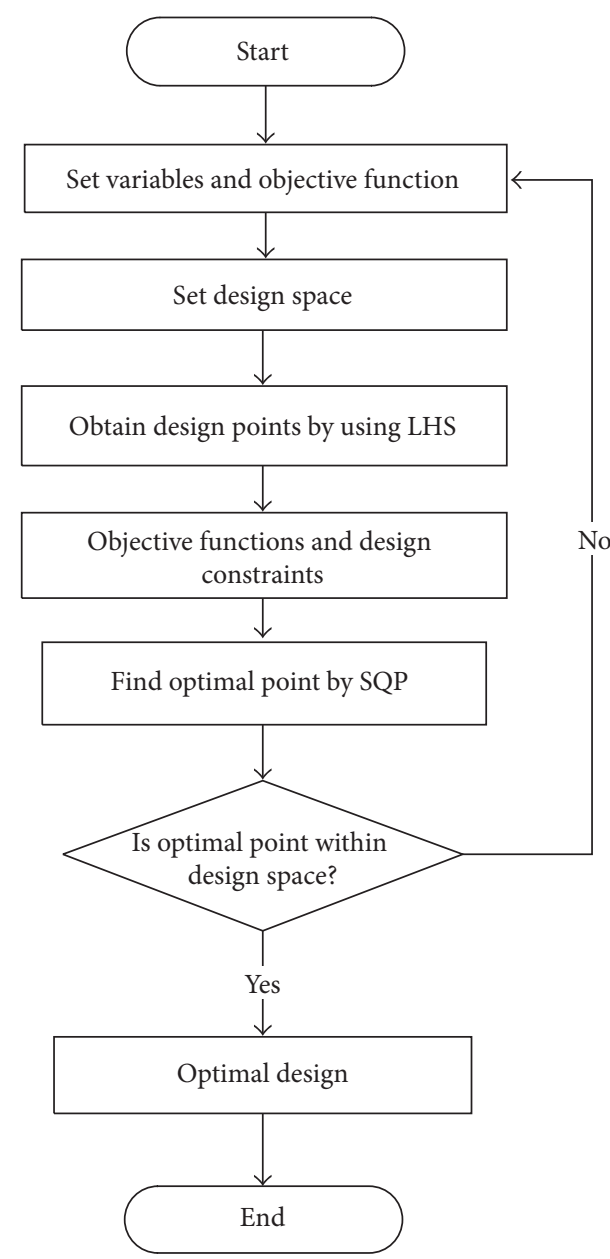

FIGURE 3: Flowchart of optimization technique.

TABLE 1: Values of design parameters.

\begin{tabular}{lc}
\hline Design parameters & Values \\
\hline$L($ in $)$ & 240 \\
$f_{c}^{\prime} /(\mathrm{psi})$ & 4,000 \\
$E_{C} /(\mathrm{psi})$ & $3.8 \times 10^{6}$ \\
$\rho\left(\mathrm{lbs} / \mathrm{ft}^{3}\right)$ & 150 \\
$f_{d y}(\mathrm{psi})$ & 66,000 \\
$E_{S}(\mathrm{psi})$ & $29 \times 10^{6}$ \\
$P_{0}(\mathrm{psi})$ & 7.2 \\
$t_{d}(\mathrm{~ms})$ & 60.7 \\
$\theta_{a}$ & $1^{\circ}$ \\
$\mu_{a}$ & 15 \\
$n$ & 50 \\
\hline
\end{tabular}

The ranges of $b$ and $h$ are given as follows in this example:

$$
\begin{aligned}
2.0 & \leq \frac{h}{b} \leq 3.5, \\
h & \leq 40 \mathrm{in} .
\end{aligned}
$$


TABLE 2: Optimal design solution.

\begin{tabular}{lcc}
\hline & Standard solution & Optimal solution \\
\hline$b$ (in) & 18 & 12.5 \\
$h$ (in) & 30 & 40.0 \\
$\rho_{1}$ & 0.0045 & 0.00318 \\
$\rho_{2}$ & 0.00235 & 0.00228 \\
$\mu$ & 9.0 & 15.0 \\
$\omega$ & 0.248 & 0.322 \\
$M_{u}$ (in.lbs) & $4.45 \times 106$ & $4.29 \times 106$ \\
$W$ & 4127.3 & 3429.7 \\
\hline
\end{tabular}

TABLE 3: Energy ratio.

\begin{tabular}{lccc}
\hline Reference & {$[24]$} & {$[25]$} & {$[26]$} \\
\hline Concrete & $1.11 \mathrm{MJ} / \mathrm{kg}$ & $3180 \mathrm{MJ} / \mathrm{m} 3$ & $1.3 \mathrm{MJ} / \mathrm{kg}$ \\
Reinforcing bar & $35.3 \mathrm{MJ} / \mathrm{kg}$ & $8.9 \mathrm{MJ} / \mathrm{kg}$ & $11.1 \mathrm{MJ} / \mathrm{kg}$ \\
$n_{E}$ & 101 & 21.8 & 27.2 \\
\hline
\end{tabular}

TABLE 4: Cost ratio.

\begin{tabular}{lccc}
\hline Reference & {$[27]$} & {$[28]$} & {$[6]$} \\
\hline Concrete & $55 £ / \mathrm{m} 3$ & $43.93 \mathrm{EUR} / \mathrm{m} 3$ & $65.65 \mathrm{USD} / \mathrm{m} 3$ \\
Reinforcing bar & $0.5 £ / \mathrm{kg}$ & $534.53 \mathrm{EUR} / \mathrm{ton}$ & $5826.30 \mathrm{USD} / \mathrm{m} 3$ \\
$n_{\mathrm{C}}$ & 70.9 & 94.9 & 88.9 \\
\hline
\end{tabular}

The design variables obtained from the standard design approach solution and the optimal design solution are shown in Table 2.

From Table 2, it is found that $h$ and $\mu$ are larger after optimization. This is explained that an increase of $h$ and $\mu$ increases the bending resistance capacity of RC beam. By optimal design, $W$ is smaller by $16.9 \%$. If $W$ is taken as the cost, it will save $16.9 \%$ of the cost after optimal design, which is very economical. The optimal design result is shown in Table 2, which proves the effectiveness of the optimal design method mentioned before.

3.2. Example 2: Effect of Section Size $(b, h)$ on the Optimal Design. Energy ratio and cost ratio vary from country to country. Then, ranges of the energy ratio $n_{E}$ and the cost ratio $n_{C}$ should be gotten before parameter analysis. Considering the uncertainties of energy ratio and cost ratio, it is reasonable to extend the ranges that are shown in Tables 3 and 4 . Therefore, $60 \leq n_{C} \leq 200$ and $10 \leq n_{E} \leq 150$ were used in this study.

Set $\theta=2^{\circ}$ and $\mu_{m} \leq 10$ and other design parameters are the same as presented in Example 1. When analyzing the effect of $b$ on optimal design, set $h=20$ in and 10 in $\leq b \leq 20$ in (Example 2(a)). When analyzing the effect of $h$ on optimal design, set $b=15$ in and 18 in $\leq h \leq 25$ in (Example 2(b)).

In order to compare the optimal results expediently, optimal design results for $b=10$ and $h=10$ were selected as the reference results. Then, optimal results were normalized by (23), where $W_{R}$ represents the reference results. Thus, the

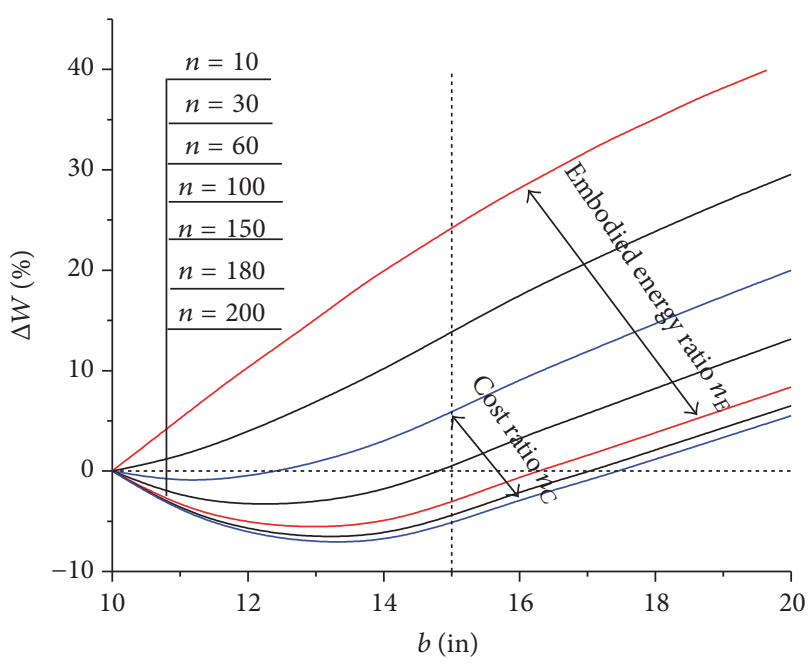

Figure 4: Effect of $b$ on $\Delta W$ (Example 2(a): $h=20$ in, 10 in $\leq b \leq$ 20 in).

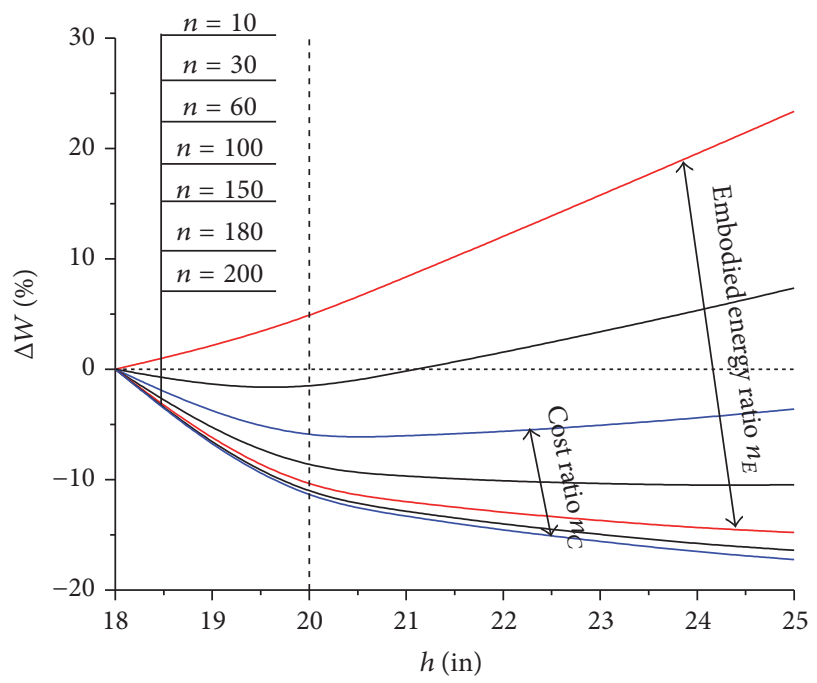

Figure 5: Effect of $h$ on $\Delta W$ (Example 2(b): $b=15$ in, 18 in $\leq h \leq$ 25 in).

smaller the value of $\Delta W$, the more effective the optimization. Normalized optimal results are shown in Figures 4 and 5.

$$
\Delta W=\frac{W-W_{R}}{W_{R}} \times 100 \% .
$$

From Figures 4 and 5, it is observed that the effect of cross section on optimization effectiveness $\Delta W$ varies with the value of $n$. When the value of $n$ is small $(n=10), \Delta W$ decreases with the increase of values of $b$ and $h$. As the value of $n$ increases, effects of $b$ and $h$ change. Ranges of $n_{E}$ and $n_{C}$ are also indicated in Figures 4 and 5. When the difference between the value of $n_{E}$ and the value of $n_{C}$ is big, an increase in costs results in a reduction in embodied energy. However, when the value of $n_{E}$ is close to the value of $n_{C}$, the cost optimal results reduce the embodied energy simultaneously.

It shall be noticed that two parameters were used as deformation constraints: $\theta$ and $\mu$. Only one parameter reached 


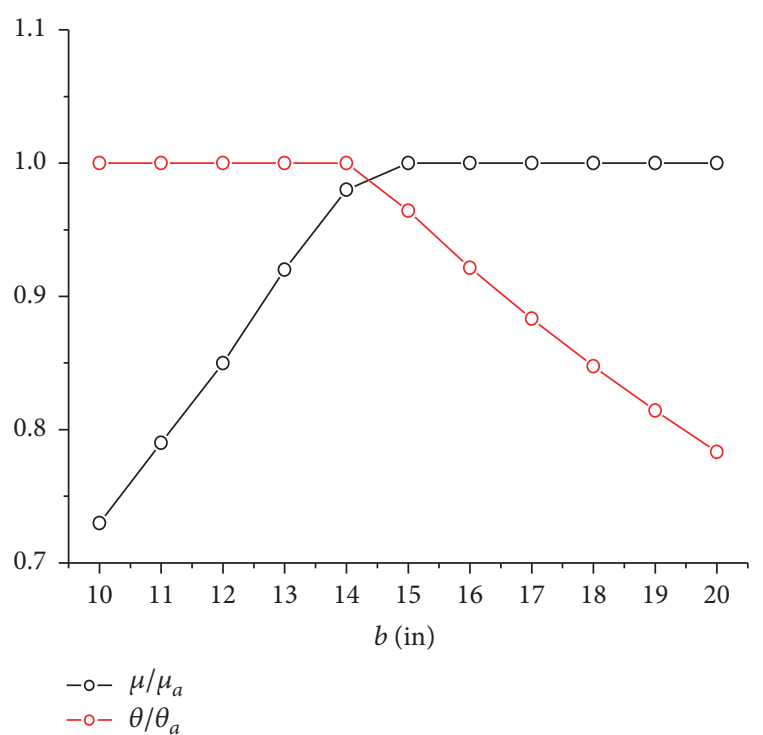

Figure 6: Values of $\mu / \mu_{a}$ and $\theta / \theta_{a}$.

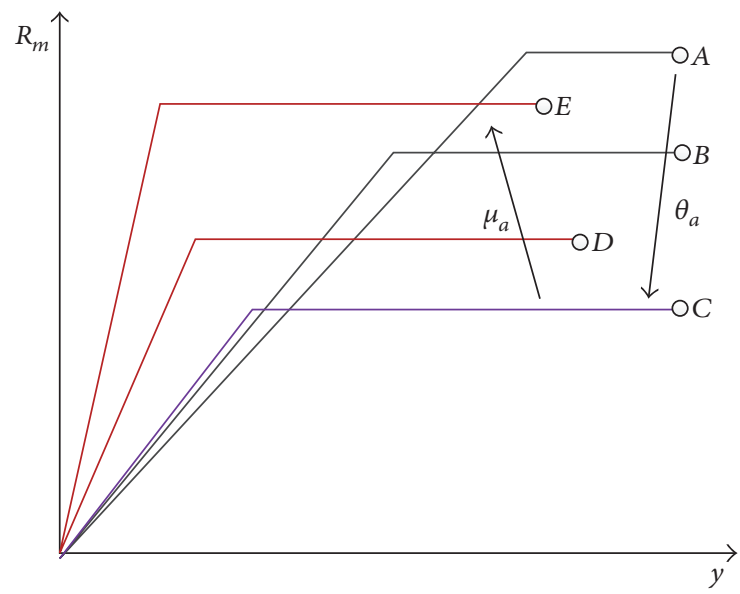

FIgURE 7: Trends in different range.

the allowed value in most cases. Take Example 2(a) as an example, the optimal values of $\mu / \mu_{a}$ and $\theta / \theta_{a}$ are shown in Figure 6 . When the value of $b$ is small, the allowed value $\theta_{a}$ is reached. As the value of $b$ increases, the value of $\theta$ decreases while the value of $\mu$ increases until it reaches the allowed value $\mu_{a}$. Two ranges were defined: $\theta_{a}$ range (in which $\theta=\theta_{a}$ ) and $\mu_{a}$ range (in which $\mu=\mu_{a}$ ). Trends are different in different ranges, shown in Figure 7. As the value of $b$ increases, the resistance changes from curve $A$ to curve $E$. Curve $A$ to curve $C$ is $\theta_{a}$ range and curve $C$ to curve $E$ is $\mu_{a}$ range. In $\theta_{a}$ range, the value of $R_{m}$ decreases as the value of $b$ increases. In $\mu_{a}$ range, the value of $R_{m}$ increases as the value of $b$ increases. Those show that the optimal results are quite different if different deformation constraints are adopted. In order to obtain a safe design, constraints of $\theta$ and $\mu$ should be considered simultaneously.

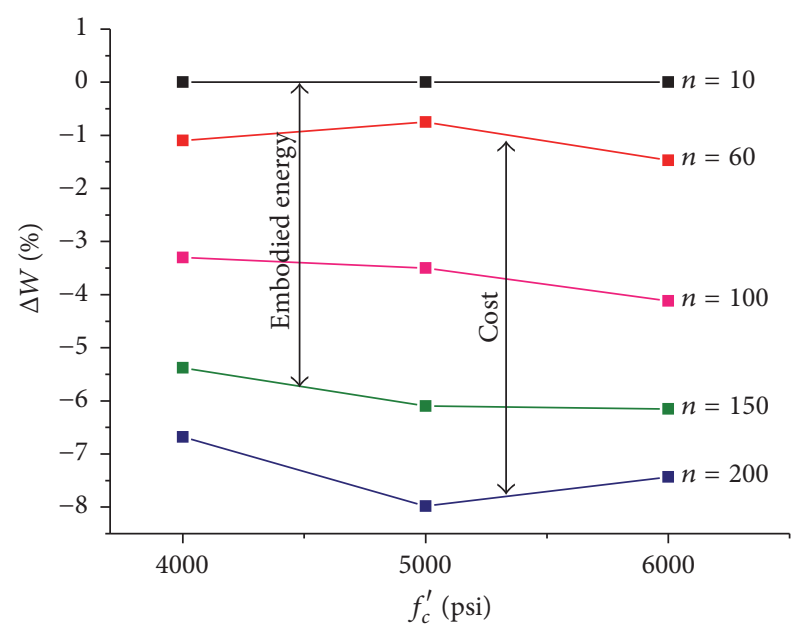

Figure 8: Effect of $f_{c}^{\prime}$ on cost and embodied energy.

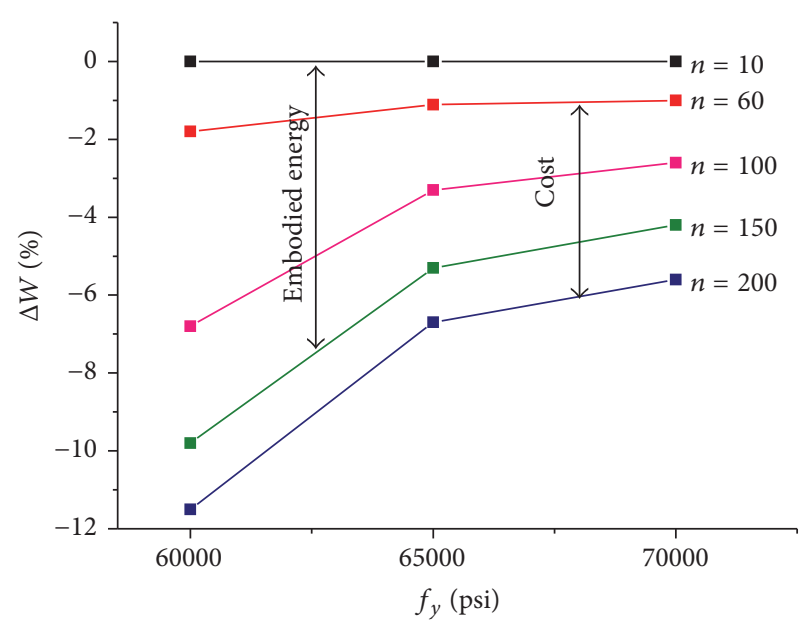

FIGURE 9: Effect of $f_{y}$ on cost and embodied energy.

3.3. Example 3: Effect of Material Strength on the Optimal Design. Values of design parameters were the same as those of Example 2(a). Optimal design results when $n=10$ were chosen as the reference results. Then, optimal design results were normalized by (23). First, an investigation was performed to study the effect of concrete compression strength $f_{c}^{\prime}$ on optimal effectiveness $\Delta W$ (see Figure 8). It is clear to find that the optimal effectiveness closely relates to $n$. However, the relationship between $f_{c}^{\prime}$ and optimal effectiveness is not clear, which is different from the conclusion under conventional load [29].

Then, an investigation was performed to investigate the effects of the yield stress of steel $f_{y}$ on optimal effectiveness $\Delta W$ (see Figure 9). As the yield stress of steel increases, $\Delta W$ decreases regardless of $n$, which means that the optimal design is very effective if the yield stress of steel is small. 


\section{Conclusions}

The sustainable design and the blast-resistance design were combined in this paper. A general optimization procedure to minimize the cost and the embodied energy of RC rectangular cross-section beam was present. The optimal design was turned into a nonlinearly constrained optimization. The optimal design was conducted using Latin hypercube sampling and the sequential quadratic programing (SQP) method. Several examples were present to investigate the optimization effectiveness. Several major conclusions are drawn as follows:

(1) The optimal results are different if different deformation constraints are adopted. In order to obtain a safe design, constraints of $\theta$ and $\mu$ should be considered simultaneously.

(2) The optimization results are closely related to the cost ratio $n_{C}$ and the embodied energy ratio $n_{E}$. When the value of $n_{E}$ is close to the value of $n_{C}$, the cost optimal results reduce the embodied energy simultaneously.

(3) The optimal design is more effective if the yield stress of steel is small. In the present study, when the yield stress of steel is decreased (from $70000 \mathrm{psi}$ to $60000 \mathrm{psi}$ ), the efficiency of optimal design will significantly increase for both cost (from 5.6\% to $11.5 \%$ ) and embodied energy (from $4.2 \%$ to $9.8 \%$ ).

\section{Competing Interests}

The authors declare that there is no conflict of interests regarding the publication of this paper.

\section{Acknowledgments}

The authors acknowledge the financial support from National Basic Research Program of China (973 Program, Grant no. 2015CB058003), National Natural Science Foundation of China (Grant nos. 51478467, 51378016, and 51210012).

\section{References}

[1] International Energy Agency, Key World Energy Statistics, International Energy Agency, Paris, France, 2005.

[2] Organization for Economic Cooperation and Development, Environmentally Sustainable Buildings: Challenges and Policies, Organization for Economic Cooperation and Development, Paris, France, 2003.

[3] World Business Council for Sustainable Development, Energy Efficiency in Buildings-Business Realities and Opportunities, World Business Council for Sustainable Development, Geneva, Switzerland, 2008.

[4] I. Paya-Zaforteza, V. Yepes, A. Hospitaler, and F. GonzálezVidosa, " $\mathrm{CO}_{2}$-optimization of reinforced concrete frames by simulated annealing," Engineering Structures, vol. 31, no. 7, pp. 1501-1508, 2009.

[5] D. Yeo and R. D. Gabbai, "Sustainable design of reinforced concrete structures through embodied energy optimization," Energy and Buildings, vol. 43, no. 8, pp. 2028-2033, 2011.
[6] G. F. De Medeiros and M. Kripka, "Optimization of reinforced concrete columns according to different environmental impact assessment parameters," Engineering Structures, vol. 59, pp. 185194, 2014

[7] V. Yepes, J. V. Martí, and T. García-Segura, "Cost and $\mathrm{CO}_{2}$ emission optimization of precast-prestressed concrete U-beam road bridges by a hybrid glowworm swarm algorithm," Automation in Construction, vol. 49, pp. 123-134, 2015.

[8] C. K. Chau, T. M. Leung, and W. Y. Ng, "A review on life cycle assessment, life cycle energy assessment and life cycle carbon emissions assessment on buildings," Applied Energy, vol. 143, pp. 395-413, 2015.

[9] F. H. Abanda, J. H. M. Tah, and F. K. T. Cheung, "Mathematical modelling of embodied energy, greenhouse gases, waste, timecost parameters of building projects: a review," Building and Environment, vol. 59, pp. 23-37, 2013.

[10] H. S. Park, H. Lee, Y. Kim, T. Hong, and S. W. Choi, "Evaluation of the influence of design factors on the $\mathrm{CO}_{2}$ emissions and costs of reinforced concrete columns," Energy and Buildings, vol. 82, pp. 378-384, 2014

[11] UFC 3-340-02, Structures to Resist the Effects of Accidental Explosions, Unified Facilities Criteria (UFC), Washington, DC, USA, 2008.

[12] D. O. Dusenberry, Handbook for Blast-Resistant Design of Buildings, Wiley Press, New York, NYUSA, 2010.

[13] F. Fedghouche and B. Tiliouine, "Minimum cost design of reinforced concrete T-beams at ultimate loads using Eurocode2," Engineering Structures, vol. 42, pp. 43-50, 2012.

[14] US Army Corps of Engineers, Methodology Manual for the Single-Degree-of Freedom Blast Effects Design Spreadsheets (SBEDS), US Army Corps of Engineers, Washington, DC, USA, 2008.

[15] Protective Design Center, Single Degree of Freedom Structural Response Limits for Antiterrorism Design (PDC TR-06-08), U.S. Army Corps of Engineers, Protective Design Center, Omaha, Neb, USA, 2008.

[16] P. Olmati, F. Petrini, and K. Gkoumas, "Fragility analysis for the Performance-Based Design of cladding wall panels subjected to blast load," Engineering Structures, vol. 78, pp. 112-120, 2014.

[17] W. L. Bounds and P. T. King, Design of Blast-Resistant Buildings in Petrochemical Facilities, ASCE Publications, Reston, Va, USA, 1997.

[18] C. Perea, J. Alcala, V. Yepes, F. Gonzalez-Vidosa, and A. Hospitaler, "Design of reinforced concrete bridge frames by heuristic optimization," Advances in Engineering Software, vol. 39, no. 8, pp. 676-688, 2008.

[19] I. Paya, V. Yepes, F. González-Vidosa, and A. Hospitaler, "Multiobjective optimization of concrete frames by simulated annealing," Computer-Aided Civil and Infrastructure Engineering, vol. 23, no. 8, pp. 596-610, 2008.

[20] A. Adamu and B. L. Karihaloo, "Minimum cost design of RC frames using the DCOC method Part I: columns under uniaxial bending actions," Structural Optimization, vol. 10, no. 1, pp. 1632, 1995.

[21] M. H. F. M. Barros, R. A. F. Martins, and A. F. M. Barros, "Cost optimization of singly and doubly reinforced concrete beams with EC2-2001," Structural and Multidisciplinary Optimization, vol. 30, no. 3, pp. 236-242, 2005.

[22] K. Schittkowski, onlinear Programming Codes: Information, Tests, Performance, vol. 183 of Lecture Notes in Economics and Mathematical Systems, Springer-Verlag, Berlin, Germany, 1980. 
[23] M. D. McKay, R. J. Beckman, and W. J. Conover, "A comparison of three methods for selecting values of input variables in the analysis of output from a computer code," Technometrics, vol. 21, no. 2, pp. 239-245, 1979.

[24] G. P. Hammond and C. I. Jones, "Embodied energy and carbon in construction materials," Proceedings of Institution of Civil Engineers: Energy, vol. 161, no. 2, pp. 87-98, 2008.

[25] CBPR, Table of Embodied Energy Coefficients, Centre for Building Performance Research (CBPR), Wellington, New Zealand, 2003.

[26] O. F. Kofoworola and S. H. Gheewala, "Life cycle energy assessment of a typical office building in Thailand," Energy and Buildings, vol. 41, no. 10, pp. 1076-1083, 2009.

[27] M. G. Sahab, A. F. Ashour, and V. V. Toropov, "Cost optimisation of reinforced concrete flat slab buildings," Engineering Structures, vol. 27, no. 3, pp. 313-322, 2005.

[28] C. Ji, T. Hong, and H. S. Park, "Comparative analysis of decisionmaking methods for integrating cost and $\mathrm{CO}_{2}$ emission-focus on building structural design," Energy and Buildings, vol. 72, pp. 186-194, 2014.

[29] D. H. Yeo and F. A. Potra, "Sustainable design of reinforced concrete structures through $\mathrm{CO}_{2}$ emission optimization," Journal of Structural Engineering, vol. 141, no. 3, 2013. 


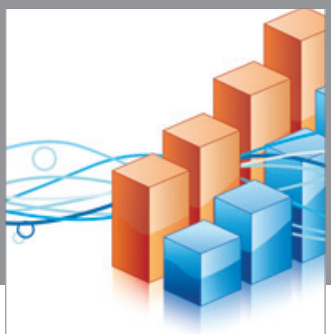

Advances in

Operations Research

vatem alat4

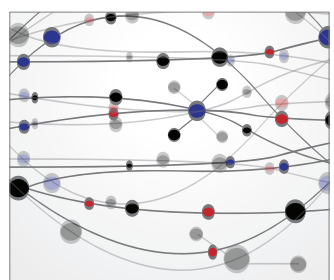

\section{The Scientific} World Journal
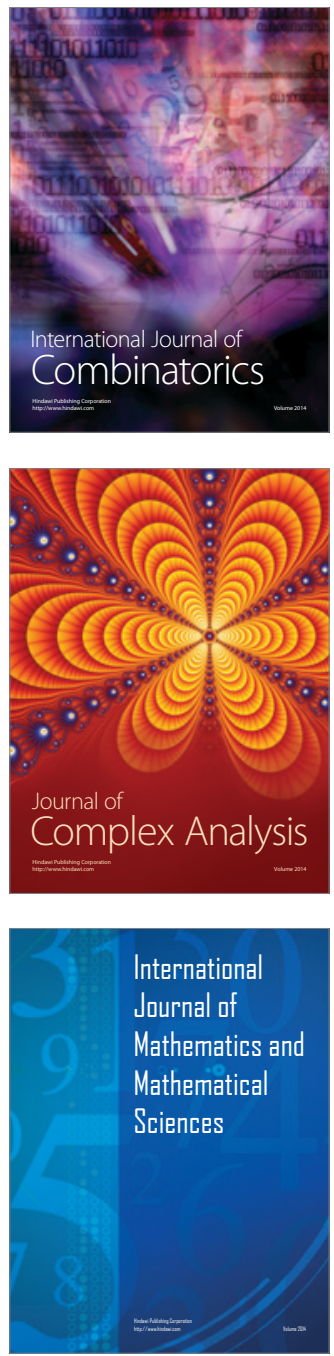
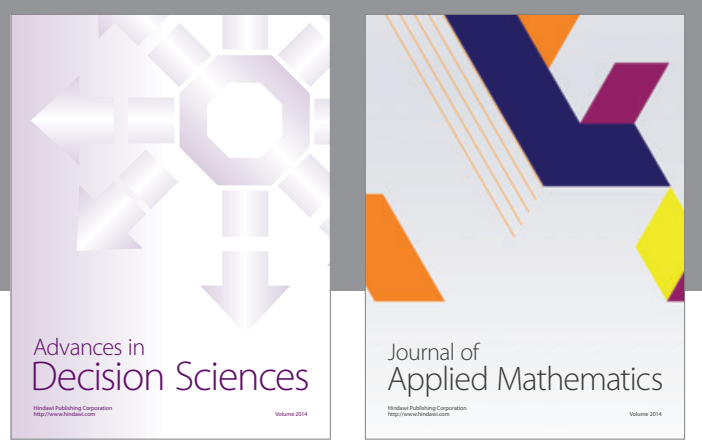

Algebra

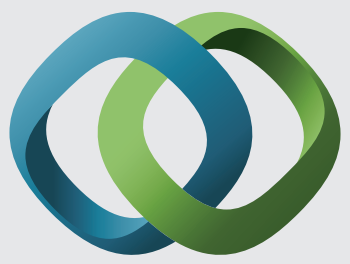

\section{Hindawi}

Submit your manuscripts at

https://www.hindawi.com
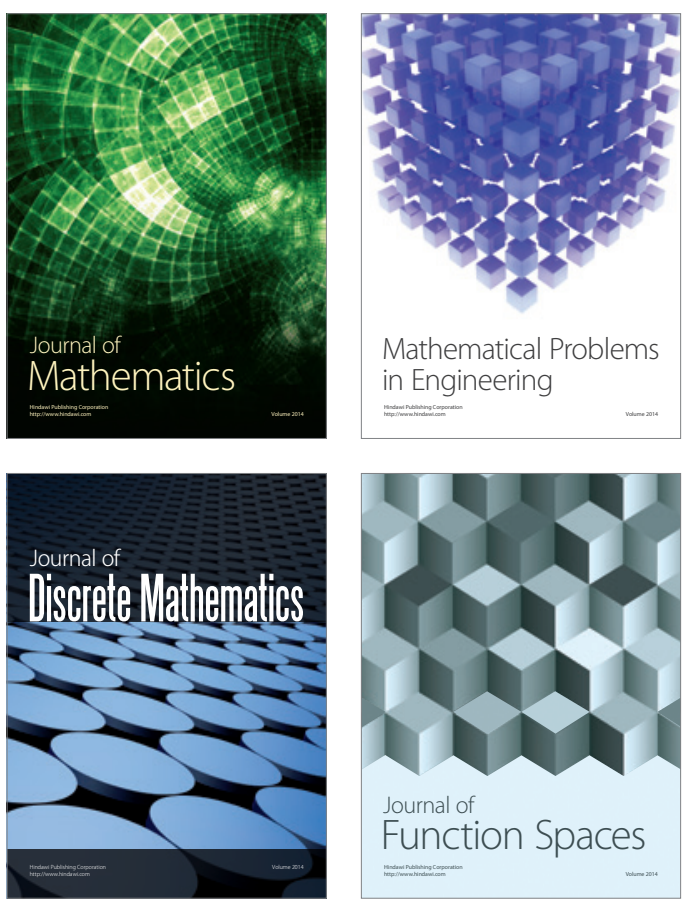

Mathematical Problems in Engineering
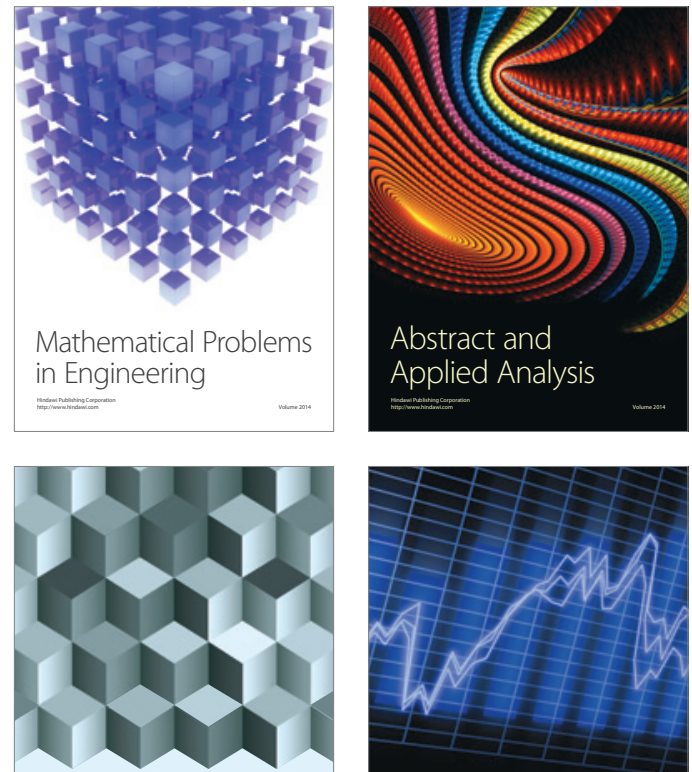

Journal of

Function Spaces

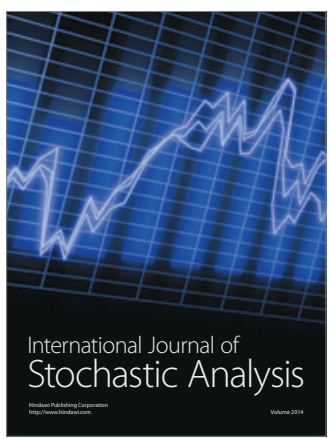

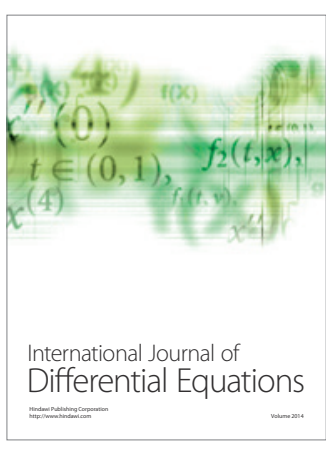
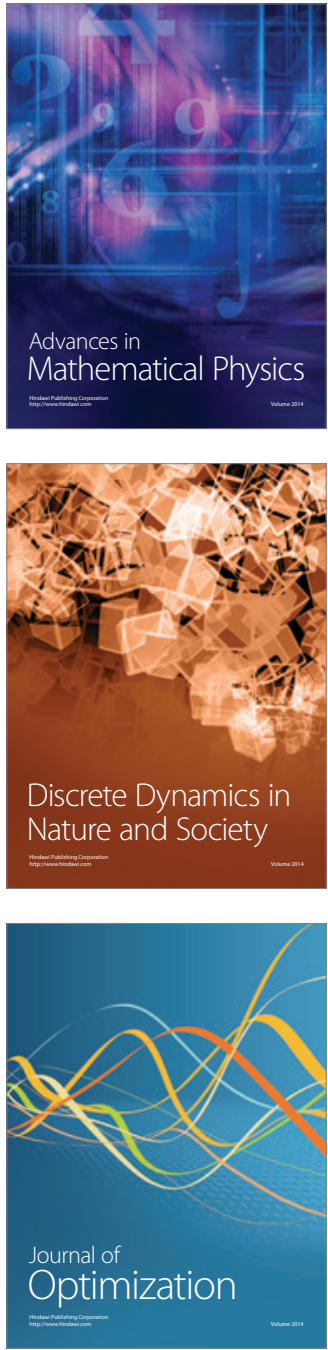